\title{
SRAP molecular markers linked to three morphological traits in Egyptian bread wheat (Triticum aestivum L.)
}

\author{
Khaled, A.G.A. ${ }^{1}$, T.M. Elameen ${ }^{2}$, A.Y.M. Ahmed ${ }^{1}$, M. Mohiy ${ }^{3}$ and I.F.O. Elshazly ${ }^{2 *}$ \\ ${ }^{1}$ Department of Genetics, Faculty of Agriculture, Sohag University, Sohag, Egypt. \\ ${ }^{2}$ Department of Genetics, Faculty of Agriculture, South Valley University, Qena, 83523, Egypt. \\ ${ }^{3}$ Wheat Res. Dep., Field Crops Res. Inst., ARC, Giza, Egypt.
}

\begin{abstract}
Sequence Related Amplified Polymorphism (SRAP) molecular technique was used for assessing the genetic diversity of eight Egyptian bread wheat (Triticum aestivum L.) genotypes. Five SRAP primers combinations were able to expose the polymorphism between the studied genotypes. The percentage of polymorphism (P \%) ranged from 40 to 79.90 $\%$. Furthermore, the Polymorphic Information Content (PIC) values for SRAP primers combination varied from 0.11 to 0.31 with an average of 0.19 . The Me5F-Em2R and Me1F-Em2R primer combination cleared higher levels of polymorphism of 66.67 and $76.90 \%$, respectively. The results of Single Marker Analysis (SMA) showed that the SRAP marker Me1F-Em2R 1320bp could be considered probably as candidate marker linked to spike length in the tested genotypes. Moreover, Me1F-Em2R 900bp and Me1F-Em2R 575bp could be considered as markers linked to plant height and tillers number /plant traits, respectively. Results of Single Marker Analysis (SMA) showed significant marker-trait associations for spike length $(P=0.04)$, plant height $(P=0.02)$ and number of tillers/plant $(P=0.03)$. Me1F-Em6R 850bp marker could be also considered as candidate markers probably linked to plant height, with a specific fragment of $850 \mathrm{bp}$ for the tolerant genotype $\left(\mathrm{P}_{1}\right)$. UPGMA cluster analysis based on SRAP markers separated the studied wheat genotypes into three significantly different clusters. The dendrogram based on morphological traits divided the studied wheat genotypes into two different clusters. The Mantel test revealed that there was a positive but non-significant correlation between the genetic similarities based on phenotypic data and SRAP marker $(\mathrm{r}=0.36, \mathrm{P}>$ $0.05)$.
\end{abstract}

Keywords: Cluster analysis; Polymorphic Information Content; Single Marker Analysis; SRAP; Wheat.

\section{Introduction}

Bread wheat (Triticum aestivum L.) is a hexaploid cultivated species $(2 n=6 x=42$, genomes AABBDD). It is the main cereal crop of rabi season and is grown in almost parts of Egypt. Due to its high nutritional value, it is placed among the most important food crops in Egypt

*Corresponding author: Ibrahim F. O. Elshazly Email: ibrahim.fathi@agr.svu.edu.eg

Received: June 4, 2021; Accepted: July 29, 2021;

Published online: July 30, 2021

(C) Published by South Valley University.

This is an open access article licensed under c(i)(-) and worldwide. In Egypt, the total grain production of wheat reached about nine million tons resulted from 1.430 million ha with 6.30 ton/ha, while 15 million tons were consummating from the wheat grains (Anonymous, 2017). In spite, the high increase in wheat production in Egypt that reached 8.8 million ton produced from 1.34 million ha with 6.57 ton/ha (FAO, 2017). However, still there is a gap between production and consumption.

Molecular markers offer a super tool for acquiring genetic information (Manifesto et al., 
2001; Roy et al., 2004) and their use withinside the evaluation of genetic variety in wheat (Barakat et al., 2010). Because they may be unbased of tissue or environment effects, plentiful and permit cultivar identity early in plant development. Among different classes of molecular marker, the Sequence-Related Amplified Polymorphism (SRAP) markers are beneficial for plant genetics and breeding due to their reproducibility, relative abundance, codominant inheritance, multi-allelic nature and suitable genome coverage (Gupta et al., 1999). SRAP is based on the amplification of Open Reading Frames (ORFs) (Li and Quiros, 2001) by targeting the regions with promoters, intronic regions and exonic regions (Wang et al., 2009). SRAP were carried out in diverse research which includes the construction of genetic linkage map (Li and Quiros 2001; Filiz, 2012; Wang et al., 2010), genetic diversity (Dong et al., 2010; Khaled et al., 2019), and evolutional study (Budak et al., 2004; Filiz et al., 2009). SRAP markers continue to be the main marker type for quantitative trait loci (QTL) studies in wheat, either alone or in combination with other types of markers, and they cover all 21 wheat chromosomes (Hu and Vick, 2003; Liu et al., 2005; Wang et al., 2005; Aneja et al., 2012). Generally, SRAP markers are greater simple, stable, reproducible and more informative than the other molecular markers. Therefore, the aim of this study was molecular characterization of eight Egyptian bread wheat (Triticum aestivum L.) genotypes using SRAP molecular markers.

\section{Materials and Methods}

\subsection{Genetic Materials}

The field experiment of the present study was carried out at the Experimental Farm of the Faculty of Agriculture, South Valley University, Qena, Egypt. SRAP marker analysis was carried out at the Biotechnology laboratory, Genetics Department, Faculty of Agriculture, Sohag
University, Sohag, Egypt. The initial plant material used in the present study consisted of eight Egyptian bread wheat genotypes (Triticum aestivum L.). Their pedigree and origin are presented in (Table 1).

\subsection{The field experiments}

In 2018/2019 winter, season, the eight bread wheat genotypes were planted on $21^{\text {st }}$ November. The field trials were organized as a Randomized Complete Block Design (RCBD) with 3 replications. Data were recorded on 10 plants chosen randomly for each genotype for Spike length, Plant height and No. of Tillers/plant.

\subsection{DNA Extraction and PCR procedure}

Genomic DNA was extracted from fresh young leaf pieces using cetyltrimethyl ammonium bromide (CTAB) protocol as described by Poresbski et al. (1997), For each genotype, 0.2g of ground leaf tissue was suspended in $2 \mathrm{ml}$ of extraction buffer $(20 \mathrm{mM}$ of EDTA, $0.1 \mathrm{M}$ of Tris$\mathrm{HCl}, 1.4 \mathrm{M}$ of $\mathrm{NaCl}, 2 \% \mathrm{CTAB}$, and $1 \%$ of PVP). The suspension was mixed well with $50 \mu$ l of beta mercapoethanol, incubated at $65^{\circ} \mathrm{C}$ for $30 \mathrm{~min}$, followed by chlorophorm-isoamyl alcohol (24:1) extraction and precipitation with $2 / 3$ of the volume of cold isopropanol and then kept at $20^{\circ} \mathrm{C}$ for one hour. The genomic DNA pellet formed after centrifugation at $5.000 \mathrm{rpm}$ for $5 \mathrm{~min}$ and washed with $1 \mathrm{ml}$ of $75 \%$ ethanol. The DNA pellet was then suspended in $100 \mu$ l of TE buffer. The quality of genomic DNA was measured in spectrophotometer Genova (UK) and in a $0.8 \%$ gel agarose stained with $0.2 \mu$ l ethidium bromide. Genomic DNA was diluted 10-fold in water prior to 35cycles of PCR amplification. The PCR assays were performed in a $25 \mu \mathrm{l}$ volume containing $12.5 \mu \mathrm{l}$ of Go Taq ${ }^{\circledR}$ Green Master Mix (Promega, Madison, USA), $3.5 \mu 1$ of primer 8pmol, $7 \mu \mathrm{l}$ of free nuclease water and $2 \mu \mathrm{l}$ of 100ng genomic DNA templates. The Thermal Cycler 96-labmet (USA) was programmed as: 1 cycle (an initial denaturing step) of $5 \mathrm{~min}$ at $95^{\circ} \mathrm{C}$, 
35 cycles of $30 \mathrm{sec}$ at $95^{\circ} \mathrm{C}$ (denaturation step), $30 \mathrm{sec}$ at $47^{\circ} \mathrm{C}$ to $58^{\circ} \mathrm{C}$ (annealing step, optimized for each primer combination), $2 \mathrm{~min} 30 \mathrm{sec}$ at $72^{\circ} \mathrm{C}$ (elongation step) and $5 \mathrm{~min}$ at $72^{\circ} \mathrm{C}$ (final extension), then stored at $8^{\circ} \mathrm{C}$. The amplified products were electrophoresed in a $1.0 \%$ agarose gel stained with $0.2 \mu 1$ ethidium bromide. The amplified fragments were visualized and photographed using UVP Bio Doc-It imaging system (USA) (Sambrook et al., 1989). Seven SRAP primer combinations were used for the assessment of the genetic diversity between studied genotypes (Table 2).

Table 1. Names, pedigree and origin of bread wheat genotypes used in the study.

\begin{tabular}{cccc}
\hline Code & Name & Pedigree & Origin \\
\hline $\mathrm{P}_{1}$ & SAKHA -93 & SAKHA 92 / TR 810328 S 8871-1S-2S-1S-0S & Egypt \\
$\mathrm{P}_{2}$ & GEMMIZA -11 & B0W"S"/KVZ"S"//7C/SERI82/3/GIZA168/SAKHA61.CGM7892-2GM- & Egypt \\
& & 1GM-2GM-1GM0GM & Egypt \\
$\mathrm{P}_{3}$ & GIZA-171 & SAKHA 93 / GEMMEIZA 9 S.6-1GZ-4GZ-1GZ-2GZ-0S & Egypt \\
$\mathrm{P}_{4}$ & SHANDWEEL-1 & SITE//MO/4/NAC/TH.AC//3*PVN/3/MIRLO/BUC. CMSS93B00567S-72Y- & 010M-010Y-010M-0HTY-0SH. \\
$\mathrm{P}_{5}$ & SAHEL-1 & N.S.732/Pim/Vee"S" & Egypt \\
$\mathrm{P}_{6}$ & SIDS-1 & HD2173/PAVON"S"//1158.57/MAYA 47 "S" SD46-4SD-2SD-ISD-OSD. & Egypt \\
$\mathrm{P}_{7}$ & MISR-2 & SKAUZ/BAV92. CMSS96M03611S-1M-010SY-010M-010SY-8M-0Y- & Egypt \\
$\mathrm{P}_{8}$ & & SAKHA-8 & 0EGY \\
\hline
\end{tabular}

\subsection{Data analysis for molecule markers}

The DNA banding patterns generated by SRAP markers was analyzed by computer programme Gene Profiler (version 4.03). The presence (1) or absence $(0)$ of each band was recorded for each genotype for all studied primers. Genetic distance was estimated according to Jaccard's (1908). To measure the informativeness of the SRAP technique in differentiating among genotypes, the polymorphic information content (PIC) was calculated according to the formula of Ghislain $e t$ al. $(1999)$ as PIC $=1-\left[(p)^{2}+(q)^{2}\right]$, where $\mathrm{p}$ is the frequency of allele band present and $q$ is frequency of allele band absent across the tested genotypes. The marker index (MI) was also calculated for SRAP primer as $\mathrm{MI}=\mathrm{PIC} \times \eta \beta$, where PIC is the mean PIC value, $\eta$ is the number of bands, and $\beta$ is the proportion of polymorphism. Analysis of variance (ANOVA) was conducted using the $0-1$ data. The association analysis was conducted using simple linear regression, for the data on individual phenotypic traits were regressed on whole $0-1$ binary marker data for each individual marker using Excel programme. The coefficient of determination $\left(\mathrm{R}^{2}\right)$ was calculated as $\mathrm{R}^{2}=1-(\mathrm{SSE} / \mathrm{SST})$, where SSE is the sum of squares of error and SST is the total sum of squares. 


\subsection{Dendrograms construction}

The genetic similarities among the studied genotypes using the SRAP results were computed and UPGMA-dendrogram was performed according to Jaccard's similarity coefficient using (NTSYS-pc version 2.20) (Applied Biostatics Inc.) (Rohlf, 2000). Mantel (1967) (Z) test had been performed to estimate the correlation between the distance's matrices conducted based on phenotypic data using Euclidean's coefficient (Sneath and Sokal, 1973) and SRAP markers. While, the genetic similarities the averages of traits were computed according to Gower general coefficient (Gower, 1971).

Table 2. Sequence and TM of the SRAP Primers are be use in this study.

\begin{tabular}{|c|c|c|}
\hline SRAP Primers & Primer Sequence $5^{\prime} \ldots \ldots \ldots . . . . . .33^{\prime}$ & TM \\
\hline $\mathrm{Me}-1(\mathrm{~F})$ & TGAGTCCAAACCGGATA & 49.00 \\
\hline $\mathrm{Me}-5(\mathrm{~F})$ & TGAGTCCAAACCGGAAG & 52.00 \\
\hline $\mathrm{Me}-7(\mathrm{~F})$ & TGAGTCCAAACCGGACG & 54.00 \\
\hline Em-2(R) & GACTGCGTA CGAATTTGA & 49.90 \\
\hline Em-3 (R) & GACTGCGTACGAATTGAC & 50.00 \\
\hline Em-5(R) & GACTGCGTACGAATTAAC & 47.00 \\
\hline Em-6(R) & GACTGCGTACGAATTGCA & 53.00 \\
\hline
\end{tabular}

\section{Results and Discussion}

\subsection{Mean Performance of the studied genotypes}

Mean performance of the eight genotypes studied are presented in Table 3. Concerning of Spike
Length, the results cleared that the best genotype was $\left(\mathrm{P}_{2}\right)$ with mean value of $17.05 \mathrm{~cm}$. Furthermore, the results indicated that the tallest ranged from $110.01 \mathrm{~cm}$ for $\left(\mathrm{P}_{2}\right)$ to $111.87 \mathrm{~cm}$ for $\left(\mathrm{P}_{8}\right)$ for Plant height trait. The results of No. of tillers/plant indicated that the highest genotype was $\left(\mathrm{P}_{8}\right)$ with mean value of 16.50 .

Table 3. Mean performance of the genotypes for traits studied.

\begin{tabular}{ccccc}
\hline Code & Genotype & Spike length $(\mathrm{cm})$ & Plant height $(\mathrm{cm})$ & No. of Tillers/plant \\
\hline $\mathrm{P}_{1}$ & SAKHA -93 & 12.25 & 88.10 & 12.90 \\
$\mathrm{P}_{2}$ & GEMMIZA -11 & 17.05 & 110.01 & 11.90 \\
$\mathrm{P}_{3}$ & GIZA-171 & 13.40 & 102.07 & 10.97 \\
$\mathrm{P}_{4}$ & SHANDWEEL-1 & 13.99 & 102.65 & 12.60 \\
$\mathrm{P}_{5}$ & SAHEL-1 & 12.46 & 109.11 & 14.67 \\
$\mathrm{P}_{6}$ & SIDS-1 & 13.77 & 107.37 & 14.76 \\
$\mathrm{P}_{7}$ & MISR 2 & 11.42 & 109.15 & 13.10 \\
$\mathrm{P}_{8}$ & SAKHA-8 & 11.96 & 111.87 & 16.50 \\
\hline
\end{tabular}




\subsection{SRAP markers}

In this study, 5 pairs out of 12 pairs SRAP primers were screened among the 8 bread wheat genotypes, and 5 pairs of them (forward and reverse) were polymorphic. A total of 49 bands were amplified, of which 27 bands (55.10\%) were found polymorphic. The total bands number were established 7 (Me7F-Em3R) to 13 (Me1FEm2R). Adding, the polymorphic band numbers varied from 3 to 10 bands for the same pairs of primers, respectively. The polymorphism percentage $(\mathrm{P} \%)$ ranged from $40.00 \%$ to $76.90 \%$ (Table 4). Mean number of total bands and polymorphic bands were 9.8 and 5.4 per primer.

Me5F-Em2R and Me1F-Em2R primers showed higher levels of polymorphism of 66.67 and $76.90 \%$. The polymorphic bands size ranged from $215 \mathrm{bp}$ to $1500 \mathrm{bp}$, which generated by Me1F-Em6R primers. In this regard, Al-Doss et al. (2010) studied that polymorphism among 6 wheat durum genotypes and used 19 SRAP primers. The results showed that 128 amplified fragments including 35\% polymorphic exposed to heat stress. These findings mean that SRAP markers are efficient to estimate genetic level of diversity in wheat genotypes and useful. In the same direction, Khaled and Hamam (2015) studied 36 bread wheat for genetic variability by SRAP. Their results showed that, the percent of polymorphism (P\%) ranged from $20 \%$ to $100 \%$. Furthermore, thirteen SRAP primers combination successfully amplified 954 fragments in bread wheat genotypes, and the general polymorphism ratio changed into $99.67 \%$, starting from 98 to 100\% (Abdelkhalik et al., 2016). Likely, Khaled et al. (2019) documented that the average of (P\%) was $62.59 \%$ between eight genotypes of bread wheat using a group of ninety-five DNA-based molecular markers of SRAP. Sequence Related Amplified Polymorphism (SRAP) markers are based on 2 primers amplification, which preferentially amplifies Open Reading Frames (ORFs) or coding areas using Polymerase Chain Reaction (PCR). It could provide high polymorphism and plentiful information to assess the genetic diversity.

\subsection{PIC and MI analysis}

In this study the index of Polymorphism Information Content (PIC) was used drastically in lots of genetic range studies (Tatikonda et al., 2009; Thudi et al., 2010). The markers value of PIC indicated that DNA markers useful for gene mapping, molecular breeding and germplasm evaluation (Peng and Lapitan, 2005). The values of PIC for primer of SRAP combos were from 0.11 (Me1F-Em6R) to 0.31 (Me1F-Em2R) with a mean of 0.19 (Table 4). The SRAP primers combinations showed, the values of marker index (MI) ranged from 0.44 (Me1F-Em6R) to 3.10 (Me1F-Em2R) with a mean of 1.18 for the combinations of primer (Table 4). Same results obtained by Khaled et al. (2019) demonstrated that the average of PIC value was 0.23. Moreover, the means of MI was 1.49 analyzing a group of ninety-five DNA-based molecular markers of SRAP.

Regarding other crops, the average of PIC value (0.19) of this work is smaller than that (0.56) observed among 143 sweet sorghum accessions (Lekgari and Dweikat, 2014) using SRAP technique.

\subsection{Single-marker analysis}

The study involved 8 genotypes of bread wheat, obtaining moderate highly genetic variability and phenotypic traits and their resistance to salinity included in this study. Using easy linear regression method, a complete of 27 polymorphic bands had been identified; three of them were extensively related to three unique traits. 
Table 4. Primers used for SRAP marker, total number of fragments detected by each pair of primers, \%P, PIC, MI and fragments sizes.

\begin{tabular}{|c|c|c|c|c|c|c|c|}
\hline \multirow{2}{*}{ 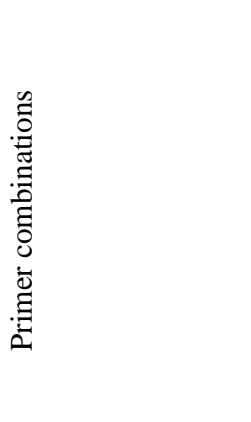 } & \multicolumn{2}{|c|}{ Amplified bands } & \multirow[t]{2}{*}{$\mathrm{P} \%$} & \multirow[t]{2}{*}{ PIC } & \multirow[t]{2}{*}{ MI } & \multicolumn{2}{|c|}{ Fragments size } \\
\hline & 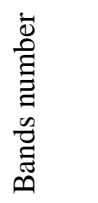 & 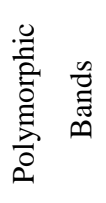 & & & & 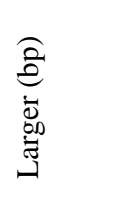 & 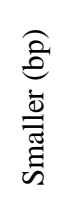 \\
\hline Me1F-Em2R & 13 & 10 & 76.90 & 0.31 & 3.10 & 1400 & 450 \\
\hline Me1F-Em5R & 10 & 4 & 40.00 & 0.18 & 0.72 & 1420 & 490 \\
\hline Me5F-Em2R & 9 & 6 & 66.67 & 0.19 & 1.14 & 1250 & 440 \\
\hline Me7F-Em3R & 7 & 3 & 42.90 & 0.16 & 0.48 & 985 & 450 \\
\hline Me1F-Em6R & 10 & 4 & 40.00 & 0.11 & 0.44 & 1500 & 215 \\
\hline Total & 49 & 27 & & & & & \\
\hline Mean & 9.8 & 5.4 & & 0.19 & 1.18 & & \\
\hline
\end{tabular}

Where: \%P: Polymorphism Percentage, PIC: Polymorphic Information Content and MI: Marker Index.

The results of Single Marker Analysis (SMA) (Table 5 and Figure 1) showed that the SRAP marker Me1F-Em2R 1320bp was regarded probably associated to spike length trait with candidate marker (Figure 1-A). Moreover, Me1FEm2R 900bp and Me1F-Em2R 575bp were regarded may be as candidate markers which were linked to plant height and tillers number per plant traits, respectively. Results of SMA showed significant regressions $(P=0.04),(P=0.02)$ and $(P=0.03)$ on spike length, plant height and number of tillers /plant, respectively.

Likely, Khaled and Hamam (2015) exhibited that the SRAP marker Me7F-Em6R 420bp was regarded to linked as candidate with marker number of kernel per spike in bread wheat. Also, Khaled et al. (2019) identified 3 SRAP molecular markers ME7F-EM5R 900bp, ME4F-EM6R 490bp and ME7F-EM6R 1250bp, probably associated to weight of grains/spike and number of grains/spike and 1000-grain weight traits respectively. Molecular markers were the most consistently for respond to the greatest extent in target environment with the prime candidates for Marker Assisted Selection (MAS). Therefore, SRAP molecular markers analysis was performed using SRAPs to determine unique and specific bands for distinguishing between varieties. Also, it is clear that some specific bands for genotypes of certain were generated by using SRAP. The SRAP primer combination Me1F-Em2R identified 2 different bands, the first (590bp) was specific for $\left(\mathrm{P}_{2}\right)$ sensitive genotype (Figure 1-A). But the second size (560bp) was for $\left(\mathrm{P}_{5}\right.$ and $\left.\mathrm{P}_{8}\right)$ moderate tolerant. Likely, the pair of primers Me1F-Em5R identified a specific fragment (950bp) for the tolerant genotype $\left(\mathrm{P}_{1}\right)$ in (Figure 1-B). In the same direction, three specific bands (yellow arrows) in (Figure 1-C) detected by 
Me5F-Em2R primer which for the sensitive genotype $\left(\mathrm{P}_{2}\right)$. Also, the pairs of SRAP primers Me7F-Em3R (Figure 1-D) identified the bands size of 550bp, respectively, Me1F-Em6R 850bp was regarded may be associated to as candidate markers with plant height and specific fragment (850bp) for the tolerant parental genotype $\left(\mathrm{P}_{1}\right)$ in (Figure 1-E). In this regard, El-Rawy and Youssef (2014) explained that drought tolerance was related with markers of SRAP were able to generate some uniquely and specific bands for genotypes of certain. Also, Ahmed et al. (2020) identified some specific bands for certain maize genotypes using SRAP technique. The associated markers each explained a maximum regression of 0.55 to 0.61 for Spike Length and Plant height traits, Number of Tillers/plant was 0.56 , respectively. The same results were obtained by Khaled and Hamam (2015) and Khaled et al. (2015) in bread wheat experiments applying SRAP molecular markers.

Table 5. Analysis of variance (ANOVA) involving coefficient of determination $\left(\mathrm{R}^{2}\right)$ for studied traits using 27 SRAP polymorphic bands.

\begin{tabular}{llllllll}
\hline Marker & Traits & S.O.V & d.f & S.S & M.S & $\mathrm{R}^{2}$ & P-value \\
\hline Me1F-Em2R 1320bp & Spike Length & Genotypes & 1 & 12.01 & $12.01^{*}$ & 0.55 & 0.04 \\
& & Error & 6 & 9.89 & 1.65 & & \\
& & Total & 7 & 21.90 & & & \\
Me1F-Em2R 900bp & Plant height & Genotypes & 1 & 249.16 & $249.16^{*}$ & 0.61 & 0.02 \\
& & Error & 6 & 162.57 & 27.09 & & \\
& & Total & 7 & 411.73 & & & \\
Me1F-Em2R 575bp & No.of Tillers/plant & Genotypes & 1 & 12.44 & $12.44^{*}$ & 0.56 & 0.03 \\
& & Error & 6 & 9.76 & 1.63 & & \\
\hline
\end{tabular}

Where: S.O.V: Source of Variance, d.f: Degrees of Freedom, S.S: Sum of Squares, M.S: Mean Squares and R². Coefficient of determination. 

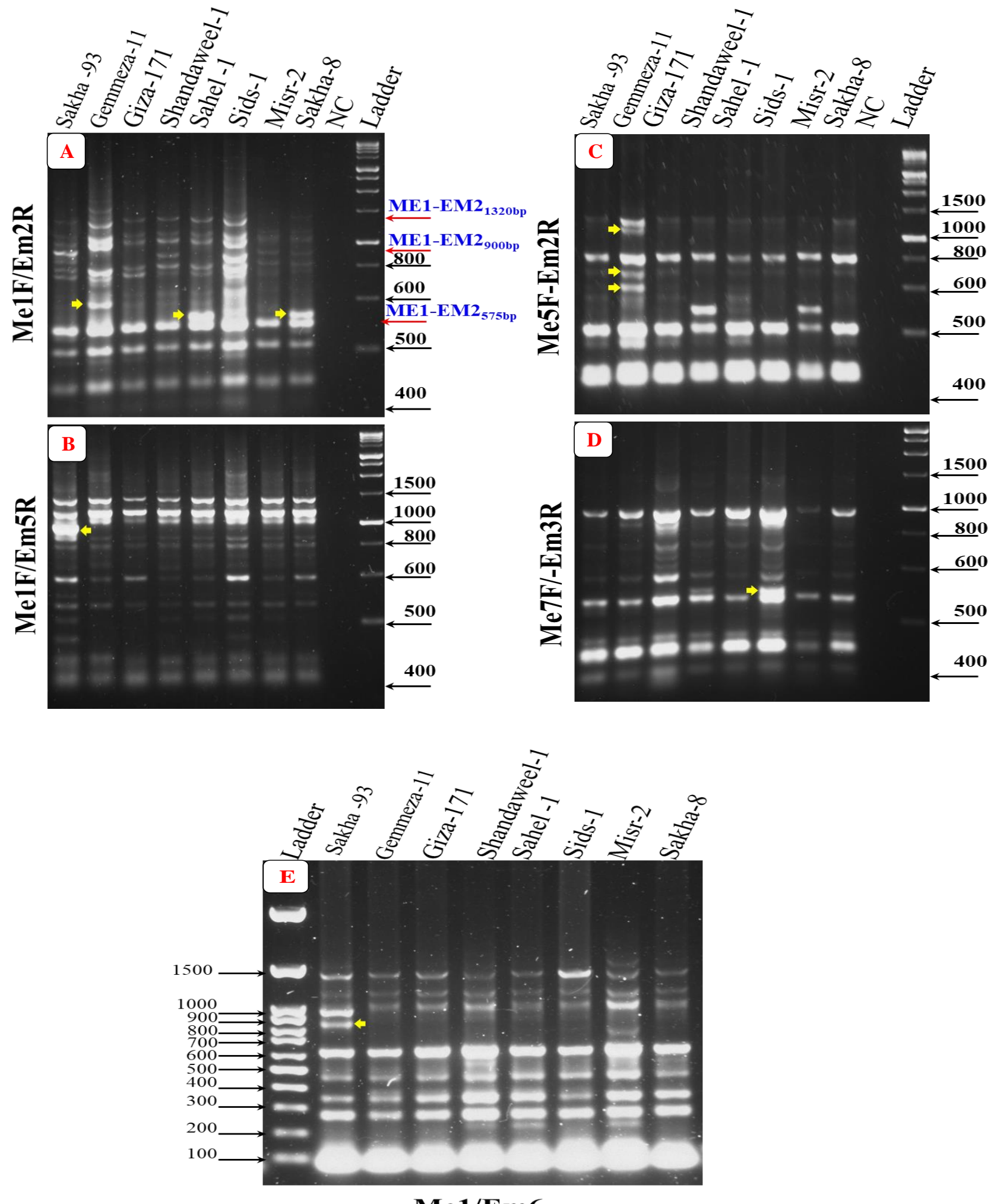

Me1/Em6

Figure 1. SRAPs profiles obtained for 8 parental genotypes of bread wheat amplified with five primers. M = 100bp DNA ladder. (Yellow arrows indicate to specific bands). 


\subsection{Cluster analysis}

\subsubsection{SRAP data analysis}

Jaccard's coefficient was used to perform a cluster analysis for the data of SRAP molecular markers. Similarity values ranged from $0.600\left(\mathrm{P}_{1}\right.$ and $\left.\mathrm{P}_{6}\right)$ to $0.857\left(\mathrm{P}_{7}\right.$ and $\left.\mathrm{P}_{8}\right)$ in (Table 6). The UPGMA cluster analysis based on the SRAP markers divided the studied genotypes into 3 significantly different clusters. The first big cluster was with genotypes $\left(\mathrm{P}_{8}, \mathrm{P}_{7}, \mathrm{P}_{5}, \mathrm{P}_{4}\right.$ and $\left.\mathrm{P}_{3}\right)$. The second cluster contains two genotypes $\left(\mathrm{P}_{6}\right.$ and $\mathrm{P}_{2}$, with similarity coefficient value of 0.725 ) which branched at similarity coefficient value of 0.681 with the first cluster. Genotype $\left(\mathrm{P}_{1}\right)$ was alone on the third cluster. The first cluster subdivided into 3 sub-clusters (Figure 2).

\subsubsection{Phenotypic data analysis}

A cluster analysis realized according to Gower general similarity coefficient (Gower, 1971) for the phenotypic data, revealed that the similarity values ranged from $0.338\left(\mathrm{P}_{2}\right.$ and $\left.\mathrm{P}_{8}\right)$ to $0.857\left(\mathrm{P}_{5}\right.$ and $\mathrm{P}_{8}$ ) (Table 7). The UPGMA cluster analysis depend on the averages of traits divided the wheat parental genotypes into 2 distinct clusters. The First cluster contains $\left(\mathrm{P}_{4}, \mathrm{P}_{2}\right.$ and $\left.\mathrm{P}_{3}\right)$ genotypes which branched with the second cluster $\left(\mathrm{P}_{7}, \mathrm{P}_{6}\right.$, $\mathrm{P}_{8}, \mathrm{P}_{5}$ and $\mathrm{P}_{1}$ ) at similarity coefficient value of 0.515 . The genotypes $\left(\mathrm{P}_{4}\right.$ and $\left.\mathrm{P}_{1}\right)$ were alone each on one branch of phylogenetic tree (Figure 3).

Table 6. The genetic similarity between the 8 studied wheat genotypes according Jaccard's coefficient obtained from 49 SRAP fragments.

\begin{tabular}{|c|c|c|c|c|c|c|c|c|}
\hline Genotypes & $\mathrm{P}_{1}$ & $\mathrm{P}_{2}$ & $\mathrm{P}_{3}$ & $\mathrm{P}_{4}$ & $\mathrm{P}_{5}$ & $\mathrm{P}_{6}$ & $\mathrm{P}_{7}$ & $\mathrm{P}_{8}$ \\
\hline Sakha-93 $\left(\mathrm{P}_{1}\right)$ & 1.000 & & & & & & & \\
\hline Gemmeza-11 $\left(\mathrm{P}_{2}\right)$ & 0.537 & 1.000 & & & & & & \\
\hline Giza-171 $\left(\mathrm{P}_{3}\right)$ & 0.639 & 0.684 & 1.000 & & & & & \\
\hline Shandaweel-1 $\left(\mathrm{P}_{4}\right)$ & 0.676 & 0.634 & 0.800 & 1.000 & & & & \\
\hline Sahel-1 $\left(\mathrm{P}_{5}\right)$ & 0.667 & 0.667 & 0.848 & 0.882 & 1.000 & & & \\
\hline Sids-1 $\left(\mathrm{P}_{6}\right)$ & 0.600 & 0.725 & 0.757 & 0.700 & 0.692 & 1.000 & & \\
\hline $\operatorname{Misr}-2\left(\mathrm{P}_{7}\right)$ & 0.697 & 0.649 & 0.727 & 0.818 & 0.813 & 0.676 & 1.000 & \\
\hline Sakha-8 $\left(\mathrm{P}_{8}\right)$ & 0.688 & 0.686 & 0.774 & 0.706 & 0.806 & 0.667 & 0.857 & 1.000 \\
\hline
\end{tabular}

Table 7. Genetic similarity among the studied bread wheat genotypes using 8 agronomic traits according to Gower general similarity coefficient

\begin{tabular}{|c|c|c|c|c|c|c|c|c|}
\hline Genotypes & $\mathrm{P}_{1}$ & $\mathrm{P}_{2}$ & $\mathrm{P}_{3}$ & $\mathrm{P}_{4}$ & $\mathrm{P}_{5}$ & $\mathrm{P}_{6}$ & $\mathrm{P}_{7}$ & $\mathrm{P}_{8}$ \\
\hline Sakha-93 $\left(\mathrm{P}_{1}\right)$ & 1.000 & & & & & & & \\
\hline Gemmeza-11 $\left(\mathrm{P}_{2}\right)$ & 0.355 & 1.000 & & & & & & \\
\hline Giza-171 $\left(\mathrm{P}_{3}\right)$ & 0.534 & 0.744 & 1.000 & & & & & \\
\hline Shandaweel-1 $\left(\mathrm{P}_{4}\right)$ & 0.549 & 0.624 & 0.712 & 1.000 & & & & \\
\hline Sahel-1 $\left(\mathrm{P}_{5}\right)$ & 0.612 & 0.426 & 0.547 & 0.637 & 1.000 & & & \\
\hline Sids-1 $\left(\mathrm{P}_{6}\right)$ & 0.665 & 0.492 & 0.580 & 0.635 & 0.835 & 1.000 & & \\
\hline $\operatorname{Misr}-2\left(\mathrm{P}_{7}\right)$ & 0.645 & 0.409 & 0.549 & 0.668 & 0.742 & 0.629 & 1.000 & \\
\hline Sakha-8 $\left(\mathrm{P}_{8}\right)$ & 0.523 & 0.338 & 0.450 & 0.556 & 0.875 & 0.762 & 0.698 & 1.000 \\
\hline
\end{tabular}




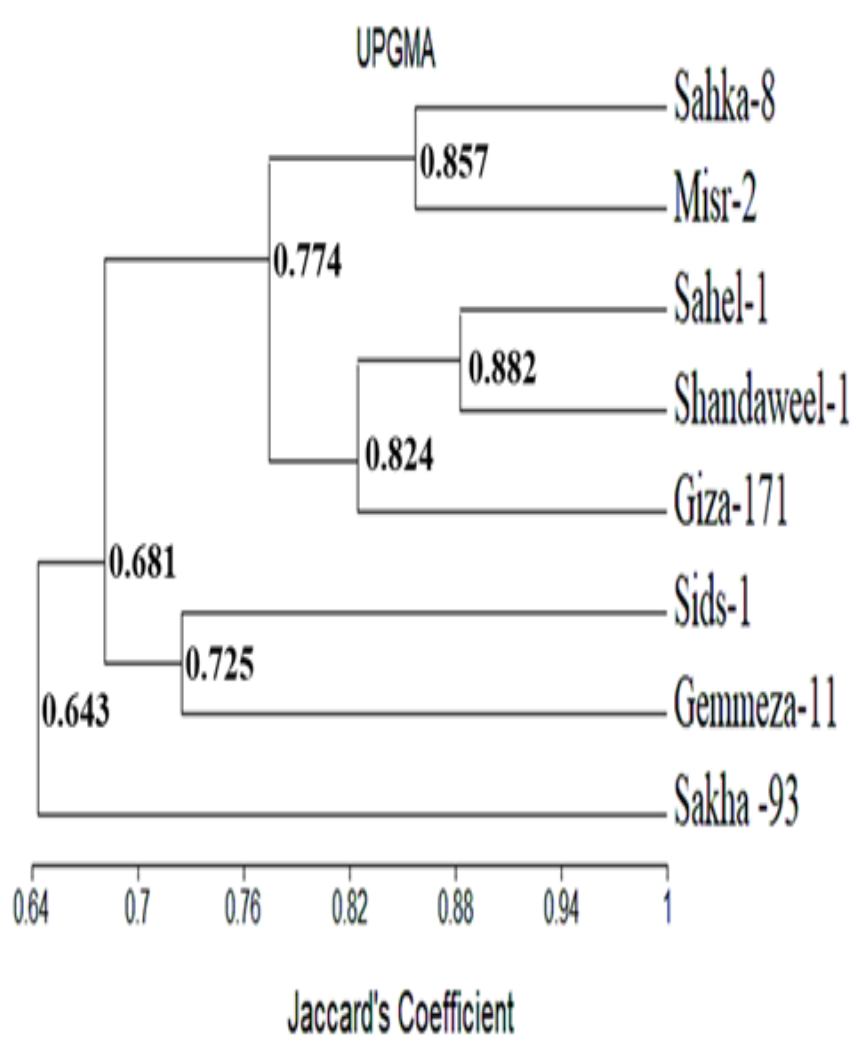

Figure 2. UPGMA-Dendogram of bread wheat genotypes using SRAP data following Jaccard's coefficient

\subsection{Combined SRAP and phenotypic markers}

The correlation ( $\mathrm{r}$ ) and the Mantel test statistic (Z) were calculated to measure the degree of relationship between the similarity matrices obtained with SRAP and phenotypic data (Figure 6). Results showed that the correlation was positive but insignificant $(\mathrm{r}=0.36, \mathrm{P}>0.05)$. Similarly, Khaled et al. (2019) revealed, the correlation between SRAP markers and means of morphological traits was positive but nonsignificant $(\mathrm{r}=0.03, \mathrm{P}>0.05)$. On the other hand, Fahmi et al. (2004) obtained a negative correlation of -0.20 between RAPD molecular markers and agronomic characterization in wheat. In addition, Roldan- Ruiz et al. (2001)

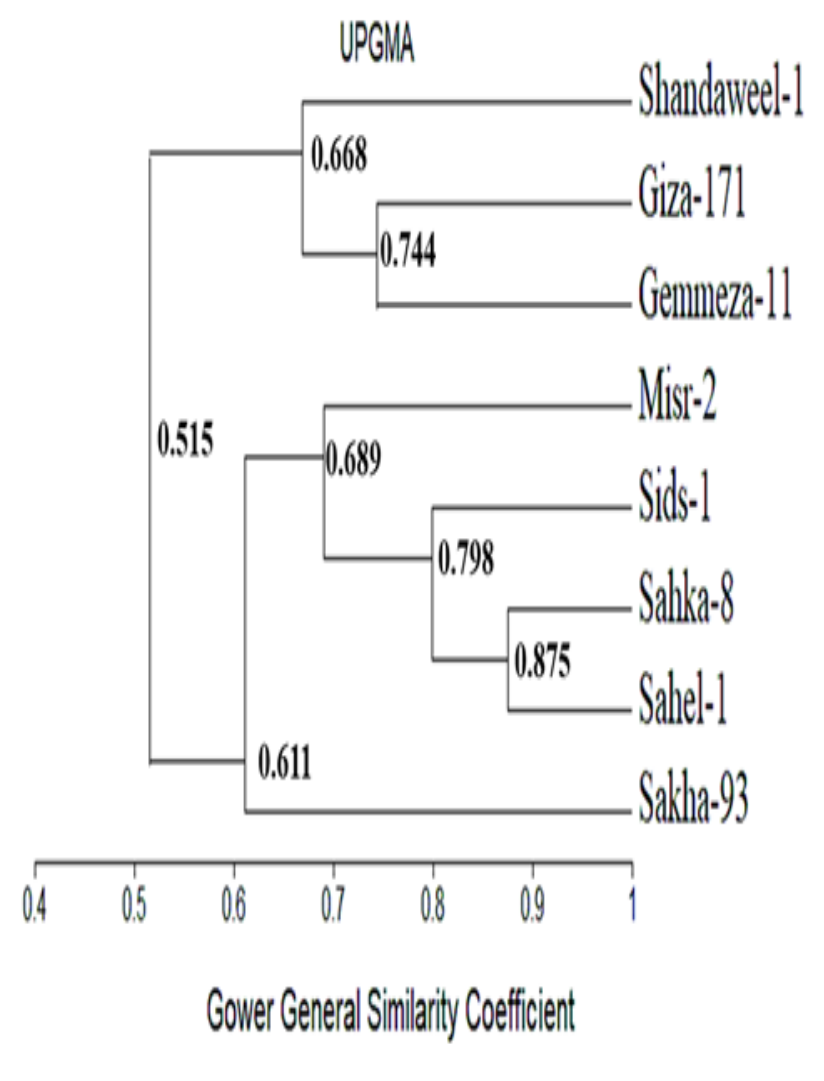

Figure 3. Dendogram of genetic similarities among studied bread wheat genotypes using eight agronomic traits according to Gower general similarity coefficient.

found also a negative correlation (-0.06) in perennial ryegrass varieties. Pandey et al. (2008) noted that DNA markers are preferable to morphological ones because they relate variability directly at genetic level and provide reliable and enormous data that permit a reproducible estimate of genetic diversity in the germplasm.

Finally, Genetic molecular markers like SRAPs may accurately assay the degree of genetic change between two genomes, but they may not necessarily reflect the divergence in terms of changes in traits of agronomic importance. 


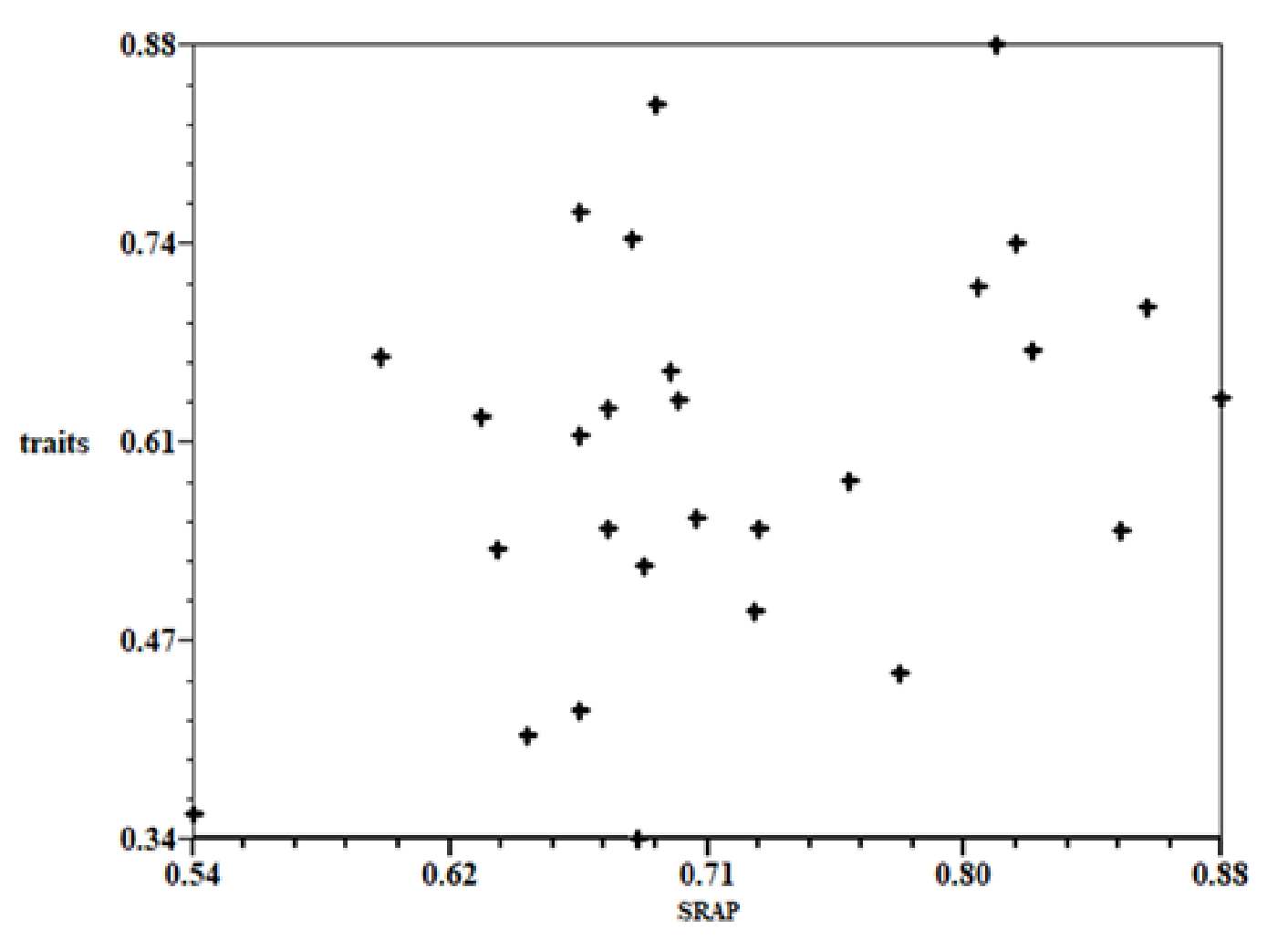

Figure 4. Correlation between similarities percent obtained from SRAP markers and studied traits for the 8 bread wheat genotypes.

\section{Conclusion}

In general, it can be concluded that the total number of DNA bands varied from 7 to 13 . The Percentage of Polymorphism (P \%) ranged from 40 to $79.90 \%$. Furthermore, values of PIC for SRAP primers combination varied from 0.11 to 0.31 with an average of 0.19 . Single marker analysis results revealed that there are three probably candidate markers could be associated to three morphological traits. UPGMA cluster analysis based on SRAP markers divided the studied wheat parental genotypes into three significant different clusters. The dendogram based on means of traits divided the wheat parental genotypes into two different clusters. Mantel (Z) test revealed that there was a positive and non-significantly correlation between the genetic similarities based on phenotypic data and SRAP marker $(r=0.36)$.
Finally, in conclusion the result of this study provided some SRAP markers associated positively with spike length, number of tillers/plant and plant height this could be used to enhance breeding programs to improve their tolerance to salinity stress and can be used in any further study to identify salt-tolerant genotypes in bread wheat.

\section{Acknowledgements}

All authors would like to acknowledge Genetics and Agriculture Botany Departments., Faculty of Agric., Sohag Univ and South Valley Univ., Egypt for kindly providing genetic materials, financial for conducting the present work. The authors wish also to acknowledge Mr. Abdallah A. Elkorifany. And thank reviewers for their valuable comments and criticisms. 


\section{References}

Abdelkhalik, S.M., Salem, A.K.M., Abdelaziz, A.R. and Ammar, M.H. (2016) 'Morphological and sequence-related amplified polymorphism based molecular diversity of local and exotic wheat genotypes' Genetics and Molecular Research, 15(2): pp. 1502-7484.

Ahmed, Y.K.Y., Abd Elmajed, M.A.H., Abduallah, R.A.I., Ali, A.A.F., Ali, H.E.M., El-Sherbeny, G.A.R., Ahmed, A.Y.M., Abdelaziz, H.S.A. and Khaled, A.G.A. (2020) 'Comparative Analysis of Genetic Diversity among Egyptian Commercial Maize Hybrids Obtained by SRAP Markers' JKAU: Met., Env. \& Arid Land Agric. Sci., 29(1): pp. 79-86.

Al-Doss, AA, Saleh, M., Moustafa, K.H., Elshafei, A.A. and Barakat M.N. (2010) 'Grain yield stability and molecular characterization of durum wheat genotypes under heat stress conditions' African J. Agric. Res.; 5: pp. 3065-3074.

Aneja, B., Yadav, N.R., Chawla, V. and Yadav, R.C. (2012) 'Sequence-related amplified polymorphism (SRAP) molecular marker system and its applications in crop improvement' Mol. Breeding, 30: pp. 16351648

Anonymous, (2017) 'Wheat production and consumption, Economic Affairs Sector' ARC, Giza, Egypt.

Barakat, M.N., Al-Doss, A.A., Moustafa, K.A., Ahmed E.I. and A. Elshafei A. (2010) 'Morphological and molecular characterization of Saudi wheat genotypes under drought stress' J. Food. Agric. Environ, 8: pp. 220-228.
Briggle, L.W. and Reitz, L.P. (1963) 'Classification of Tritium species and of wheat varieties grown in the United States' U.S. Dept. of Agriculture Bulletin, pp 1278.

Budak, H., Shearman, R.C., Gaussoin, R.E. and Dweikat I. (2004) 'Application of Sequence related Amplified Polymorphism Markers for Characterization of Turfgrass Species' Hort. Sci., 39: pp. 955-958.

Dong, P., Wei, Y.M., Chen, G.Y., Li, W., Wang, J.R., Nevo, E. and Zheng, Y.L. (2010) 'Sequence-related amplified polymorphism (SRAP) of wild emmer wheat (Triticum dicoccoides) in Israel and its ecological association' Biochemical Systematics and Ecology, 38: pp. 1-11.

El-Rawy, M.A. and Youssef, M. (2014) 'Evaluation of drought and heat tolerance in wheat based on seedling traits and molecular analysis' J. Crop Sci. Biotech, 17: pp. 183189.

Fahmi, A.I., Nagaty, H.H., Eissa, R.A. and Abdel-Hameed M.I. (2004) 'Comparison of genetic relationships based on morphological, RAPD and Microsatellite markers in hexaploid wheat' Alexandria Journal of Agricultural Research, 49: pp. 4560.

FAO (Food and Agriculture Organization). (2017) 'Statistics Division' United States. Wheat Sector Review. http://www.fao.org.

Filiz, E. (2012) 'Genetic Diversity analysis of CIMMYT bread wheat (Triticum aestivum L.) lines by SRAP markers' Electron. J. Plant Breed, 3: pp. 956-963.

Filiz, E., Ozdemir, B.S., Tuna, M. and Budak, H. (2009) 'Diploid Brachypodium distachyon of Turkey: molecular and morphological 
analysis' In the Proceeding of the $5^{\text {th }}$ International Symposium on the Molecular Breeding of Forage and Turf. Edited by $\mathrm{T}$. Yamada and G. Spangenberg. Springer, pp. 83-89.

Ghislain, M., Zhang, D., Fajardo, D., Hanuman, Z. and Hijmans, R. (1999) 'Marker assisted sampling of the cultivated Andean potato (Solanum phureja) collection using RAPD markers' Genetic Resources and Crop Evolution, 46: pp. 547-555.

Gower, J.C. (1971) 'A General coefficient of similarity and some of its properties' Biometrics, 27 (4): pp. 857-871.

Gupta, P.K., Varshney, R.K., Sharma, P.C. and Ramesh, B. (1999) 'Molecular markers and their applications in wheat breeding' Plant Breed., 118: pp. 369-390.

Hu, J. and Vick, B.A. (2003) 'Target region amplification polymorphism: a novel marker technique for plant genotyping' Plant Mol. Biol. Rep., 21: pp.289-294.

Jaccard, P. (1908) 'Nouvelles recherches sur la distribution florale' Bulletin de la Societe Vaudoise des Sciences Naturelles, 44 : pp.223-270.

Khaled, A.G.A. and Hamam, K.A. (2015) 'Association of molecular markers with phenotypic traits of Bread Wheat genotypes' Egyptian Journal of Genetics and Cytology, 44: pp. 115-130.

Khaled, A.G.A., El-Sherbeny, G.A.R. and Elsayed, H.M.A. (2019) 'Three SRAP molecular markers linked to yield component traits in wheat' Asian Journal of Research and Review in Agriculture, 1(1): pp. 25-35.

Khaled, A.G.A., Motawea, M.H. and Said, A.A. (2015) 'identification of ISSR and RAPD markers linked to yield traits in bread wheat under normal and drought conditions' $J$. of Genet. Eng. And Biotech., 13: pp. 243-252.

Lekgari, A. and Dweikat, I. (2014) 'Assessment of genetic variability of 142 sweet Sorghum germplasm of diverse origin with molecular and morphological markers' Open Journal of Ecology, 4: pp. 371-393.

Li, G. and Quiros, C.F. (2001) 'Sequence-related amplified polymorphism (SRAP), a new marker system based on a simple PCR reaction' its application to mapping and gene tagging in Brassica, Theor. Appl. Genet., 103: pp. 455-461.

Liu, Z.H., Anderson, J.A., Hu, J., Friesen, T.L., Rasmussen, J.B. and Faris, J.D. (2005) 'A wheat inter-varietal genetic linkage map based on microsatellite and target region amplified polymorphism markers and its utility for detecting quantitative trait loci' Theor. Appl. Genet., 111: pp. 782-794.

Manifesto, M.M., Schlatter, A. Hopp, H.E., Suarez, E.Y. and Dubacovsky, J. (2001) 'Quantitative evaluation of genetic diversity in wheat germplasm using molecular markers' Crop Science., 41: pp. 682-690.

Mantel, N. (1967) 'The detection of disease clustering and a generalized regression approach' Cancer Research, 27: pp.209-220.

Pandey, S., Kumar, S., Rai, M., Mishra, U. and Singh, M. (2008) 'Assessment of genetic diversity in Indian ash gourd (Benincasa hispida) accessions using RAPD markers' Proceedings of IXth EUCARPIA meeting on genetics and breeding of Cucurbitaceae (Pitrat M, ed.), INRA, Avignon, France, pp. 59-66. 
Peng, J.H. and Lapitan, N.L.V. (2005) 'Characterization of EST-derived microsatellites in the wheat genome development of eSSR markers' Funct. Integr. Genomics, 5: pp. 80-96.

Porebski, S., Bailey, L.G. and Baum, B.R. (1997) 'Modification of a CTAB DNA extraction protocol for plants containing high polysaccharide and polyphenol components' Plant Molecular Biology Reporter, 15: pp. 815.

Powell, W., Morgante, M., Andre, C., Hanafey, M., Vogel, J., Tingey, S. and Rafalski, A. (1996) 'The comparison of RFLP, RAPD, AFLP and SSR (microsatellite) markers for germplasm analysis' Molecular Breeding, 2: pp.225-238.

Rohlf, F.J. (2000) 'NTSYS-pc: Numerical taxonomy and multivariate analysis system' Version 2.1 Exeter Software, Setauket, USA.

Roldan-Ruiz., Van Eeuwijk, F.A., Gilliland, T.J., Dubreuil, P., Dillmann, C., Lallemand, J., De Losse, M. and Baril, C.P. (2001) 'A comparative study of molecular and morphological methods of describing relationships between perennial ryegrass (Lolium perenne L.) varieties' Theoretical Applied Genetics, 1203: pp. 1138-1150.

Roy, J.K., Lakshmikumaran, M.S., Balyan, H.S. and Gupta, P.K. (2004) 'AFLP-based genetic diversity and its comparison with diversity based on SSR, SAMPL, and phenotypic traits in bread wheat' Bio. Gen., 42: pp. 43-59.
Sambrook, J., Fritsch, E.F. and Maniatis, T. (1989) 'Molecular cloning' a laboratory manual $2^{\text {nd }}$ Edition. Cold Spring Harbor, New York: Cold Spring Harbor Laboratory Press.

Sneath, P.H.A. and Sokal, R.R. (1973) 'Numerical Taxonomy' Freeman, San Francisco, California, pp. 513.

Tatikonda, L., Wani, S.P., Kannan, S., Beerelli, N., Sreedevi, T.K., Hoisington, D.A., Devi, P. and Varshney, R.A. (2009) 'AFLP-based molecular characterization of an elite germplasm collection of Jatropha curcas L.' A biofuel plant. Plant Sci. 176: pp.505-513.

Thudi, M., Manthena, R., Wani, S.P., Tatikonda, L., Hoisington, D.A. and Varshney, R.A. (2010) 'Analysis of genetic diversity in Pongamia (Pongamia pinnata L. Pierre) using AFLP markers' J. Plant Biochem. Biot. 19: pp. 209-216.

Wang, G., Pan, J.S., XZ, L.I., He, H.L. and Wu, A.Z. (2005) 'Construction of a cucumber genetic linkage map with SRAP markers and location of the genes for lateral branch tasits' Sci. China Ser., 48: pp. 213-220.

Wang, X., Liu, G., Chang, R., Han, J. and Guo, E. (2009) 'Optimization of annealing temperature of SRAP-PCR in 5 temperate fruits' Geno. Appl. Biol., 28: pp. 525-528.

Wang, Y., Sun, X., Tan, B., Zhang, B., Xu, L., Huang, M. and Wang, M. (2010) 'A genetic linkage map of Populus adenopoda Maxim. 3 P. Alba L. hybrid based on SSR and SRAP markers' Euphytica, 173: pp. 193-205. 